\title{
SECOND REPORT ON THE RESULT OF CROSSING JAPANESE WALTZING MICE WITH EUROPEAN ALBINO RACES.
}

\author{
Br A. D. DARBISHIRE, Balliol College, Oxford.
}

ThE present paper is an account of the continuation of work, the first part of which was published in the last number of this Journal. It contains, first, an additional record of the results of crossing Japanese waltzing mice with albino mice, embodying the previously recorded nine families and adding eleven new ones; and secondly the result of pairing hybrids resulting from such crosses, and of crossing these hybrids with albinos.

\section{Crosses between Japanese Walting and Allino Mice.}

The number of young obtained from such crosses has increased since the last paper from 48 to 154 ; but the uniformity of the result (the almost universal presence of patches of colour like that of the house-mouse) bas not been maintained: there have appeared besides more yellow mice, black mice, and black and white.

The classification of colours in the hybrid has therefore had to be re-organized. The hybrids nearly always shew a considerable amount of white: they are now classified according to the amount of whiteness into five groups: each group is then subdivided into five classes according to the colour itself.

Group 1 (Fig. 1) has more white and less extent of coloured patches than the normal waltzing mouse. The distributiou of colour on a waltzer is shewn in Fig. 6.

Group 2 (Fig. 2) has abnut as much white as a normal waltzing mouse.

Group 3 (Fig. 3) has less white (i.e. greater extent of coloured patches) than a waltzer.

Group 4 (Fig. 4) has still less white and leads on to

Group 5 (Fig. 5) which has no pure white: but the belly is whitish not gray.

Group 6 contains mice whose bellies are nearly the same colour as their backs. A gray mouse of group $6(6 c$ or $6 d)$ is therefore indistinguishable from a house-mouse. 


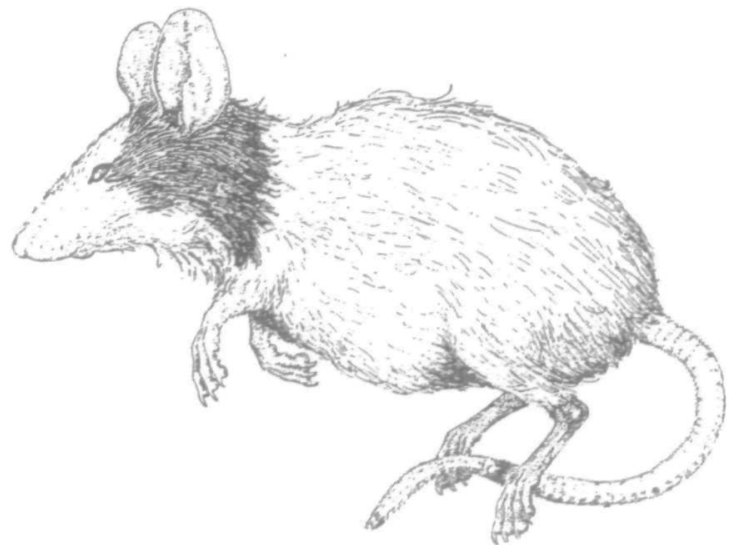

Fig. 1.

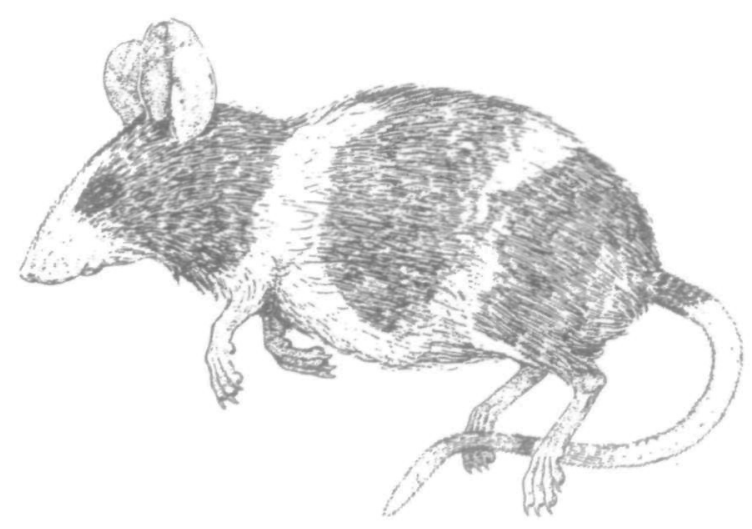

Fro. 3.

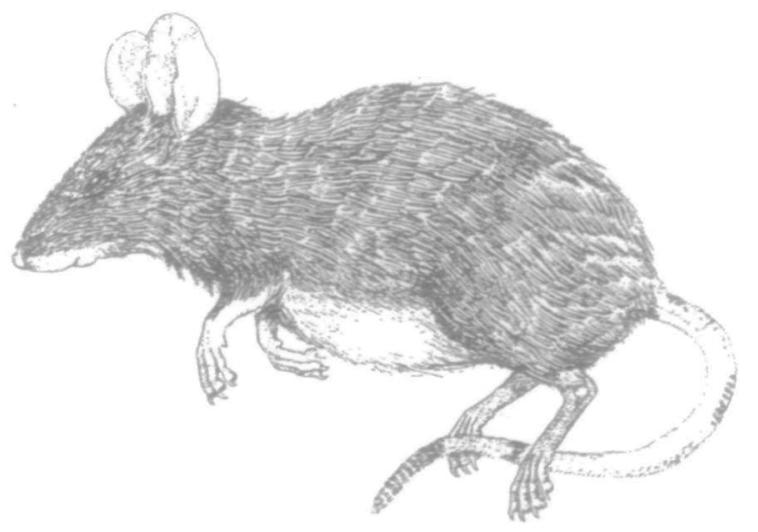

FIe. 5.

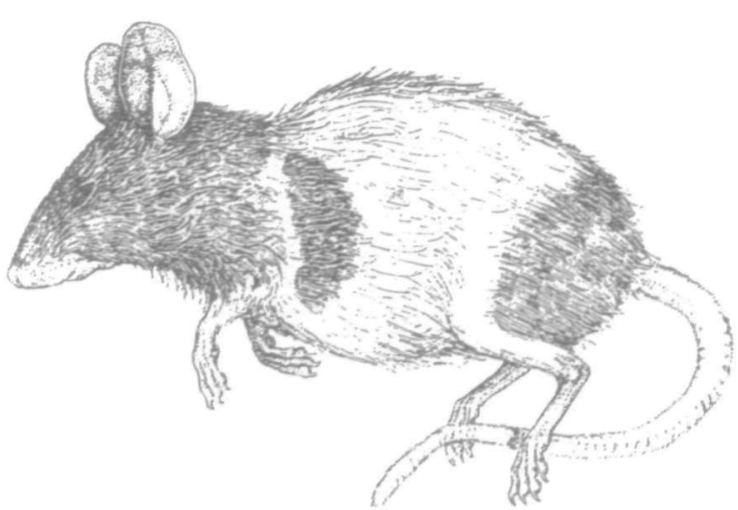

Fra. 2.

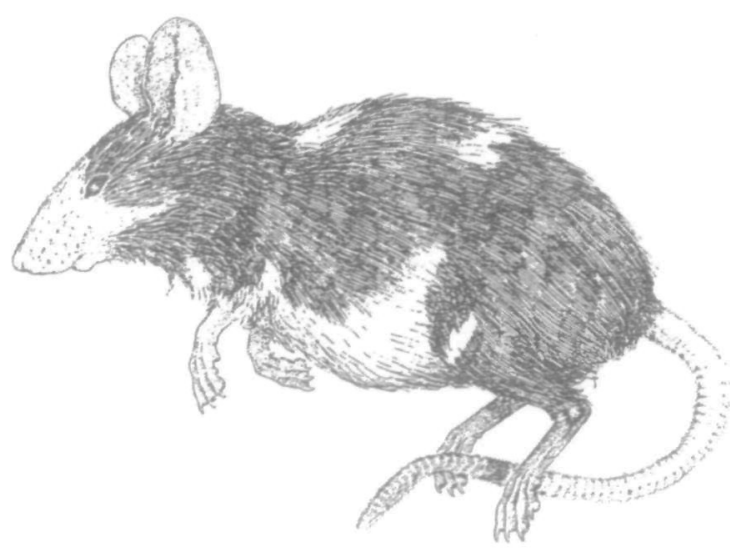

Fio. 4.

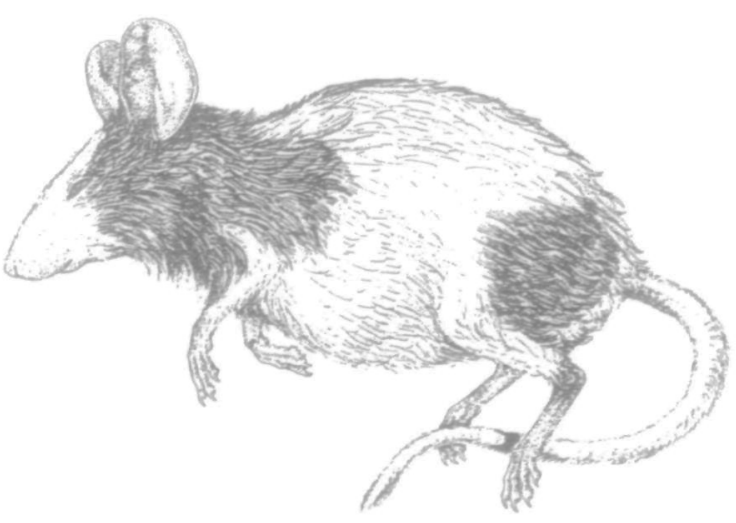

Fio. 6. 
The individuals of each group are then classified according to the colour of the coloured patches.

Class $a=$ yellow.

Class $b=$ fawn yellow.

$\left.\begin{array}{l}\text { Class } c=\text { pale wild colour } \\ \text { Class } d=\text { dark wild colour }\end{array}\right\}$ (i.e. that of the house-mouse).

Class $e=$ black,

and Class $f=$ "lilac" = pale blue gray; at present only exhibited by the offspring of hybrids.

It is not suggested that these form one colour series. Table I. shews the distribution of colour and the colour itself in all the individuals of twenty families produced by crossing waltzing with albino mice. All the mice in the Table have black eyes.

TABLE I.

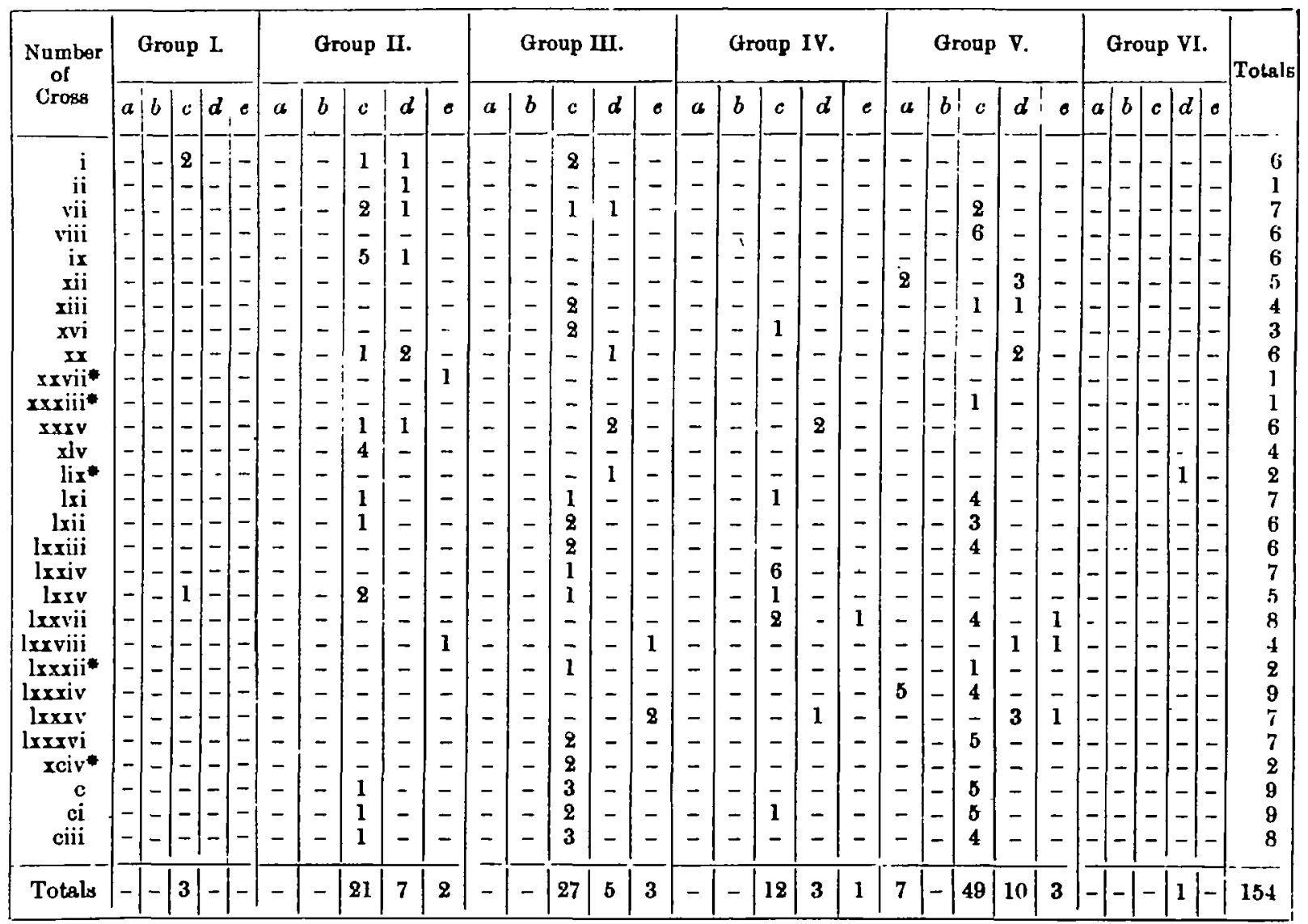

- In these crosses the parents were, $q$ waltzing mouse $\times \delta$ albino; in all the rest the parente were $\&$ albino $\times \delta$ waltzer. 
Fron the following re-classification of the above Table $I$. the frequency of degrees of whiteness umong 154 hybrids will be at unce evident.

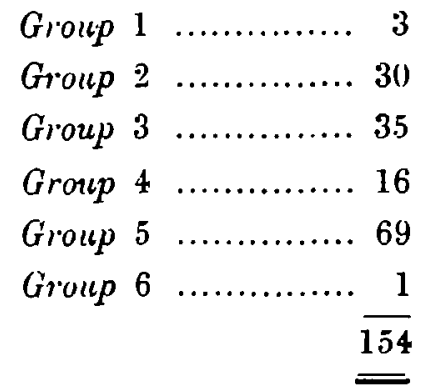

That is to suy the majority of hybrids have coluured patches in, roughly, the same place as the waltzers have; or ure wild-culuured inice except for the belly.

The following arrangement shews the frequency of colours among 154 hybrids.

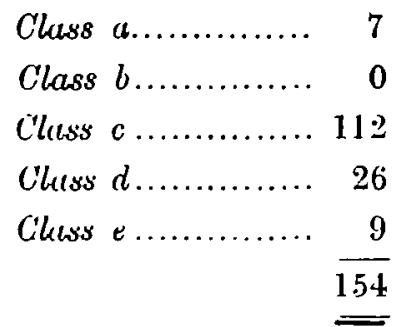

That is to say by firr the greater number of hybrids exhibit wild coluur.

Offspring of Hybirids.

Hybrids have been paired inter se and crossed with albinus.

A. Offspring of puirs of Hybrids.

The number of mice which waltz in this generation is cight. At present nine albinos have appeared: the actual ariangement of the colours and the colours themselves are here shewn: the letter $q$ indicates that the nouse exhibits waltzing movements, and $p$ that it has piuk eyes. It is unuecessary to say that albinos have pink eyes.

$$
\begin{aligned}
& H_{7} \text {. } \quad 2 d \times \delta 2 c \text {. } \\
& 3 \text { Young. } 2 f(w p), 2 a(p), 26 . \\
& H_{8} \text {. } \quad 1 c \times \delta 2 c \text {. } \\
& 4 \text { Young. } 3 b(p), 3 c, 4 a(p), 4 a(p) \text {. } \\
& \text { H. } \quad \text { } 2 d \times \delta 3 c \text {. } \\
& 5 \text { Young. } 3 a, 3 b, 3 b, 3 e(w), 3 f \text {. } \\
& H_{\text {12. }} \text { \& } 2 c \times \delta 2 c \text {. } \\
& 7 \text { Young: } 4 \text { albinos, } 3 b(w p), 3 b(p), 3 c \text {. }
\end{aligned}
$$




$$
\begin{aligned}
& H_{\text {18. }} \quad+2 c \times \delta 3 c \text {. } \\
& 7 \text { Young. } 2 \text { albinos, 2c, 2c, 2c, 2c(w), 4e (w). } \\
& H_{20} \quad q 2 c \times \delta 2 c \text {. } \\
& 6 \text { Young. Albino. Albino }(w), 2 c(w), 3 c(w), 2 e, 2 f \text {. } \\
& H_{20} \quad q 2 c \times \delta^{3} 3 \text {. } \\
& 5 \text { Young. Albino, 2e, 2c, 4e, 4d. }
\end{aligned}
$$

That is to say there are 37 young from 14 hybrid parents of degrees of whiteness jncluded in Groups 2 and 3 . The young may be classified according to degrees of whiteness and according to their colour.

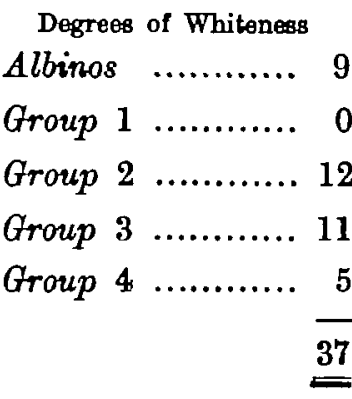

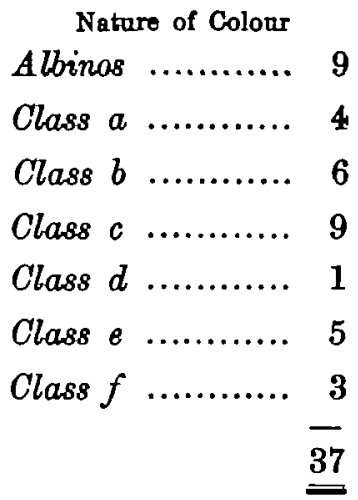

B. Offspring of Bybrids and Albinos.

The following is a record of young produced by crossing a hybrid with an albino.

$H_{1} . q$ albino $\times \sigma^{7} 3 c$.

4 Young. 5c, 5c, 5c, 5c.

$H_{2} . \quad q$ albino $\times$ o $3 \mathrm{c}$.

9 Young. 5 albinos and $4 e, 4 d, 4 d, 5 d$.

$H_{4} \quad q$ albino $\times \delta 5 \mathrm{c}$.

5 Young. 2 albinos and $5 c, 5 d, 6 e$.

$H_{s} . \quad q$ albino $\times \delta 5 c$.

5 Young. 1 albino and $6 d, 6 d, 6 d, 6 c$.

$H_{\text {. }} \quad q$ albino $\times \delta^{7} 5 c$.

4 Young. 2 albinos and $6 d, 6 d$.

$H_{11} . \quad q$ albino $\times \delta 3 d$.

6 Young. 5 albinos and $6 e$.

$H_{1 s} \quad q 2 c \times \delta$ albino.

5 Young. 2 albinos and $3 c, 6 e, 6 e$.

$H_{13} . \quad+\dot{\delta} c \times \delta$ albino.

3 Young. 1 albino and $5 d, 6 e$. 
$H_{14} . \quad q 5 c \times \delta$ albino.

6 Young. 4 albinos and $2 c, 3 e$.

$H_{15} . \quad q$ albino $\times \delta$ jc.

8 Young. 4 albinas, 3a, 3a, 6a, $3 e$.

$H_{17} . \quad+$ albino $\times \delta 5 \mathrm{c}$.

5 Young. 2 albinos, 3e, 3d, 6d.

$H_{\text {r. }} \quad q$ albino $\times \delta 5 \mathrm{c}$.

6 Young. 3 albinos, 4d, 4d, 6d.

$H_{\mathbf{3}} . \quad q$ albino $\times \delta 3 c$.

4 Young. 1 albino, 6e, 5d, 5d.

$H_{\text {s. }} \quad q 5 c \times \delta$ albino.

2 Young. 5d, $5 c$.

$H_{\mathfrak{n}} . \quad q 5 d \times \delta$ albino.

1 Young. 1 albino.

$H_{\mathbf{n}}$.. $5 c \times \delta$ albino.

6 Young. 2 albinos and $6 c, 6 c, 4 c, 6 e$.

$H_{\mathbf{x}} . \quad q$ albino $\times \delta^{7} 5 \mathrm{c}$.

9 Young. 4 albinas and $6 e, 6 e, 6 e, 6 e, 4 c$.

That is to say there is a fairly sharp segregation into albino and wild-coloured mice. Out of 88 young there are 39 albino, 31 wild-coloured, 15 black and 3 yellow mice.

\section{Discussion of Results.}

\section{The First Generation.}

As Table I. shews, the first generation has not a uniform colour: any modification of Mendel's hypothesis involves the uniformity of the first generation. For it is one of the Mendelian principles that segregation of characters does not occur until the generation produced by pairing individuals of the first (hybrid) generation. The generation, thus produced, essentially consists of $25 \%$ organisms with the recessive character and $75 \%$ with the dominant; and this not only in the case of a simple character, but in that of a complex one; for example the hybrids produced by Mendel's crossing a white flowered with a purple flowered (a complex colour according to Mendel) bean were all purple. But the offspring produced by the pairing of these purple hybrids exhibited the most marked heterogeneity. The essential point is that segregation of however complex characters never occurs before the second generation*.

Now in these mice this segregation seems to take place in the first generation, for there appear in it besides the wild colour, yellow and black, as can be seen from Table I.

* G. Mendel : "Verauohe mit Pflanzen-Hybriden," Verhandl. des Naturforsch. Ver. Brilnn, rv. Band. 1865 (Abhandlangen), pp. 34, 85. 
The view that albinism is "recessive" in Mendel's sense implies that albinos of any ancestry, provided they themselves are really albino, will behave in the same way when crossed. Now, the young of all the albinos are not the same and at the end of my last paper it was pointed out that a difference in the kind of the litter corresponded to a difference in the ancestry of the albino mother: that is to say, that wild-coloured mice only appeared in the litters of pure-bred albinos: and the generalization that the more in-bred a mouse was, the less power it had of transmitting its whiteness, was suggested. The evidence brought forward for this were the results of von Guaita who in four crosses between waltzing mice and albinos which were in-bred for 29 generations always got absolutely wildcoloured mice; aud my own results consisting of nine such crosses. This generalization is borne out by the additional eleven litters which have appeared since my last paper was written; as a classification of litters into (a) those from cross-bred albinos and (b) those from pure-bred albinos will readily shew (Table II.).

TABLE II.

\begin{tabular}{|c|c|c|c|c|c|c|}
\hline & Group 1 & Group 2 & Group 3 & Group 4 & Group 5 & Gronp 6 \\
\hline (a) Young from cross-brod alibinos & 2 & 11 & 8 & 4 & 4 & - \\
(b) Young from pure-bred albinos & - & 13 & 23 & - & 60 & 1 \\
\hline
\end{tabular}

In my previous paper I think I did not sufficiently emphasize the difference which seems to me to exist between in-bred and pure-bred mice: the above table is certainly of pure-bred mice; but what is not certain is whether the relative inability to transmit whiteness among pure-bred mice is due to the fact of their being pure-bred, or in-bred. Pure-bred mice usually are in-bred and von Guaita's unquestionably were; but this does not help us to decide whether the relative inability to transmit whiteness is due to in-breeding or pure-breeding; it only shews that it is not impossible that it may be due to in-breeding. The meanings of these terms should be clearly understood; there are two pairs of categories, one pair in which cross-bred is antithetic to pure-bred, and another pair in which out-bred is antithetic to in-bred, the former pair referring to the presence or absence of any other colour than white in the ancestry of the mouse, the latter pair to the distance or nearness of relation of the parents, grandparents, etc. of the mouse under consideration. And before the cause of the great preponderance of the number of wild-coloured mice in the litters of pure-bred over the number of those in the litters of cross-bred albinos can be ascertained waltzing mice must be crossed with in-bred and out-bred pure-bred albinos and in-bred and out-bred cross-bred albinos. (Such kinds of albinos are being reared as quickly as possible.) Whatever the explanation be, the fact remains that the ancestry of a white mouse does make a difference in the character of its offspring when crossed with a waltzing mouse.

- The 60 in the table includes the 7 yellow mice $5 a$ in which there is no whiteness. 


\section{The Second Generation.}

It will be seen by inspection of the tables recording the offspring of hybrids, that when a hybrid is paired with a hybrid the offspring form a much more heterogeneous collection than does the offspring from a hybrid and a white in which the young are more sharply segregated into white and wild-coloured. And this difference is coincident with, if not causally connected with a difference in the ancestry of the two sets of young. For the heterogeneous offspring of two hybrids have a more complex ancestry than do the less variable offspring of a hybrid and an albino; and it may be a fact of similar meaning that the hybrids produced by crossing a waltzing mouse with a cross-bred albino are more heterogeneous than those produced by a similar cross in which the albino, however, was pure-bred (see Table II.)-in both cases the more heterogeneous collection of offspring comes from parents of which the ancestry is more complex; that is to say the young of the cross-bred albinos are more heterogeneous than those of the pure-bred; and the young produced by pairing two hybrids are more heterogeneous than those produced by crossing hybrids with albinos.

No theory of compound allelomorphs such as that put forward by Mendel will account for this striking difference between the variability of the two groups of offspring.

Remembering that $6 c$ or $6 d$ indicates a mouse indistinguishable from the common Mus musculus, the curious fact will be noticed that only one such appeared among 154 hybrids of the first generation, whereas out of the 88 offspring of a cross between a hybrid and an albino there were 10 . This result may be parallel with that obtained by Darwin when he crossed a white fantail with a black barb and also a barb with a spot and then crossed the mongrel bard fantail with the mongrel barb spot and got " a bird of as beautiful a blue colour, with the white loins, double black wing-bar, and barred and white-edged tail-feathers, as any wild rack-pigeon I"; i. e. reversion, in both cases, did not occur until the third generation.

The facts so far observed which are in possible accordance with some form of Mendelian hypothesis are (1) the apparently regular appearance of albinos when hybrids are crossed with albinos, although the evidence at present available does not suffice to shew whether these occur in Mendelian proportions (50\% albino and $50 \%$ hybrid) or not, (2) the well-known fact that albinos of any ancestry when paired together produce albino young, exceptions to this rule being at least very rare, and (3) the appearance of waltzing and albino mice in the second hybrid generation.

The first of these results although not inconsistent with the truth of Mendel's hypothesis cannot be taken as proof that this hypothesis applies; for a similar result is observed in such cases as that of human eye-colour where Mendel's Laws have been shewn not to hold $t$. 


\section{A. D. Darbishirk}

Postscript, added Feb. 12, 1903.

The mice, resulting from a first cross between albinos and pink-eyed waltzing mice, are now 203, all the individuals having dark eyes, while none have wholly white fur, and none waltz. In the second generation, there are 66 mice produced by pairing hybrids; of these 13 are pink-eyed albinos, and 17 have pink eyes and coats more or less coloured. In the same generation there are 205 individuals produced by crossing albinos with hybrids; of these 111 are albinos, the remainder having dark eyes and some colour in the coat.

The proportions of albinos and of individuals not albino are not in disagreement with Mendel's results, but the exhibition of these results in Mendelian form depends on the adoption of a quite artificial category of coat-colours; for albinism includes only pure whiteness of cart, while coloured caats include the whole range of conditions from white with small patches of pale yellow to dark "wild colour" or black.

The inheritance of eye-colour is not in accordance with Mendel's results. For since pink eyes occur in particoloured mice, the possession of pink eyes must on Mendel's view depend on a separate embryonic element from that which determines coat-colour. Pink eyes are however not "dominant," since the two pinkeyed parents of the first generation always produce dark-eyed young. For the same reason pink eyes are not "recessive." Yet although pink eyes disappear in the first generation (the result of crossing two pink-eyed parents) they reappear in the second; but a correlation is then established between coat-colour and eyecolour which is strong in the offspring of hybrids paired together, and at present perfect in the offspring of hybrids and albinos. The behaviour of eye-colour is thus in every respect discordant with Mendel's results. 